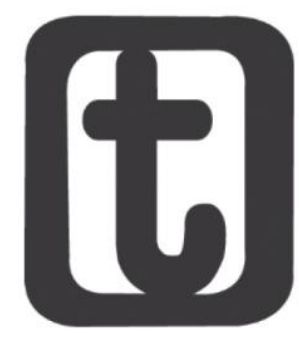

\title{
SERVIÇO SOCIAL E MOVIMENTOS SOCIAIS: DEBATENDO ARTICULAÇÕES NO ÂMBITO DA FORMAÇÃO PROFISSIONAL
}

\author{
Social Work and Social Movements: debating articulations within the scope of professional \\ training
}

Cleier Marconsin

https://orcid.org/0000-0001-8417-5243

\section{RESUMO}

Este texto trata das expressões das articulações do Serviço Social com os movimentos sociais, na formação profissional, tendo como referência as Diretrizes Curriculares aprovadas pela ABEPSS. Os dados e análises são parte dos resultados da pesquisa "Serviço Social e Movimentos Sociais: um estudo no âmbito da formação profissional”, realizada durante o estágio pós-doutoral, do Programa de Estudos Pós-Graduados em Serviço Social, da PUC-SP, entre 2018 e 2019. Debate a formação profissional no que se refere aos movimentos sociais e suas relações com o Serviço Social, nas disciplinas dos currículos da graduação e nos projetos de pesquisa e extensão desenvolvidos em 11 Unidades de Ensino dos estados do Rio de Janeiro e São Paulo, públicas (estaduais e federais), comunitárias (PUCs) e privadas (presenciais e a distância), as quais compõem a Amostra Intencional. Observa-se que o ideário neoliberal interferiu regressivamente na proposta das Diretrizes Curriculares da ABEPSS, consolidada pela Comissão de Especialistas da Associação, quando da sua aprovação, pelo Conselho Nacional de Educação do Ministério da Educação (CNE/MEC), em 2002. O estudo realizado nas Unidades da Amostra Intencional constata as resultantes das interferências desse ideário, notadamente, com a ênfase posta na privatização do ensino superior, no país, persistente ao longo dos últimos anos.

\section{PALAVRAS-CHAVE}

Movimentos Sociais. Formação Profissional. Neoliberalismo. Privatização do Ensino Superior.

\section{ABSTRACT}

This text deals with the expressions of the articulations of Social Service with social movements, in professional training, having as reference the Curricular Guidelines approved by ABEPSS. The data and analyzes are part of the results of the research "Social Work and Social Movements: a study within the scope of professional training", carried out during the post-doctoral internship, of the Post-Graduate Studies in Social Work Program, at PUC-SP, between 2018 and 2019. Debates professional training with regard to social movements and their relations with Social Work, in the disciplines of the undergraduate curricula and in research and extension projects developed in 11 Teaching Units in the states of Rio de Janeiro and São Paulo, public (state and federal), community (PUCS) and private (face-to-face and distance), which make up the Intentional Sample. It is observed that the neoliberal ideology interfered regressively in the proposal of the ABEPSS Curricular Guidelines, consolidated by the Association's Specialists Commission, when it was approved by the National Education Council of the Ministry of Education (CNE / MEC), in 2002. The study carried out in the Units of the Intentional Sample, it verifies those

\footnotetext{
* Assistente Social. Doutorado em Serviço Social. Professora Faculdade de Serviço Social da Universidade do Estado do Rio de Janeiro (UERJ). E-mail: cleiermarconsin@gmail.com.
}

DOI 10.22422/temporalis.2020v2on40p30-46 Commons Atribuição 4.0 Internacional (https://creativecommons.org/licenses/by/4.o/deed.pt_BR), que permite copiar e redistribuir o material em qualquer suporte ou formato, bem como adaptar, transformar e criar a partir deste material para qualquer fim, mesmo que comercial. O licenciante não pode revogar estes direitos desde que você respeite os termos da licença.

Temporalis, Brasília (DF), ano 20, n. 40, p. 30-46, jul./dez. 2020. | ISSN 2238-1856 


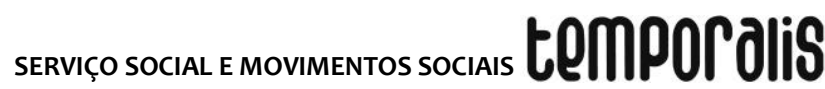

resulting from the interferences of this idea, notably, with the emphasis placed on the privatization of higher education in the country, persistent over the last years.

KEYWORDS: Social Movements. Professional Training. Neoliberalism. Privatization of Higher Education.

Aceito em: 19/10/2020.

\section{INTRODUÇÃO}

$\mathrm{N}$ a pesquisa "Serviço Social e Movimentos Sociais: um estudo no âmbito da formação profissional”, as expressões das relações do Serviço Social com os movimentos sociais foram estudadas em diferentes unidades de ensino que compuseram a Amostra Intencional, ${ }^{1}$ tendo como referência a direção social posta pelas Diretrizes Curriculares da ABEPSS, aprovadas em 1996 e consolidadas pela Comissão de Especialistas da ABEPSS ${ }^{2}$, em 1999, em contraposição às Diretrizes Curriculares aprovadas pelo Conselho Nacional de Educação - CNE/MEC, em 2002.

Ao termos as Diretrizes Curriculares da ABEPSS como referência, importa destacar a sua construção pela corrente profissional denominada por Netto (1991) de intenção de ruptura, que tem como substrato teórico a tradição marxista. Parte do processo de Renovação do Serviço Social (NETTO, 1991) a partir de meados da década de 1970, essa corrente se constitui no período de efervescência da luta contra a ditadura militar, no Brasil. Destacamos, no processo sócio-histórico, a ruptura pública, coletiva do Serviço Social com o conservadorismo, fruto da reorganização sindical da categoria e sua inserção política nas lutas sociais, na crise da autocracia burguesa a partir de 1978. O Congresso Brasileiro de Assistentes Sociais (CBAS), realizado em 1979, conhecido como "Congresso da Virada", 3 constitui-se marco viabilizador desse processo, o qual publicizou

\footnotetext{
${ }^{1}$ Como não havia possibilidade de estudar o objeto em todas as Unidades de Ensino do país, optamos por um tipo de amostragem denominado Amostra Intencional, que concebe a representatividade com base no peso, na realidade, dos elementos estudados e “[...] na qualidade das informações obtidas deles [...]”, não em sua quantidade (FONTANELLA; RICAS; TURATO, 2008, p. 20). A seleção da amostra teve como espaço territorial os Estados do Rio de Janeiro e de São Paulo, porque são dois estados cujo processo de desenvolvimento capitalista marca a constituição do Serviço Social, sendo neles que se deu a gênese da profissão. Em termos do ensino de graduação e de pós-graduação são estados de referência no circuito universitário. Considerando a natureza do financiamento, o período sócio-histórico em que foram implantados (nas públicas, consideramos cursos criados antes e após a data da aprovação das Diretrizes Curriculares da ABEPSS - 1996), privadas (comunitárias e presencial e a distância), a amostra intencional ficou composta da seguinte maneira: Cursos em universidades públicas estaduais e federais existentes até 1996: Universidade do Estado do Rio de Janeiro (UERJ); Universidade do Estado de São Paulo (UNESP). Universidade Federal do Rio de Janeiro (UFRJ). Cursos criados com o Programa de Apoio a Planos de Reestruturação e Expansão das Universidades Federais (REUNI), a partir de 2007: Universidade Federal do Estado do Rio de Janeiro (UNIRIO) e Universidade Federal do Estado de São Paulo - Campus Baixada Santista (UNIFESP). Universidades Comunitárias: Pontifícia Universidade Católica do Rio de Janeiro (PUC/Rio) e Pontifícia Universidade Católica de São Paulo (PUC/SP). Universidades ou faculdades privadas presenciais: Universidade Castelo Branco (UCB) - Rio de Janeiro; Faculdades Metropolitanas Unidas (FMU) São Paulo; Universidades ou faculdades privadas de ensino a distância: Universidade Estácio de Sá (UNESA) - Rio de Janeiro; Universidade Paulista (UNIP) - São Paulo.

${ }^{2}$ A Comissão de Especialistas do Ministério da Educação (MEC) é composta por profissionais indicados pela ABEPSS.

3 No Congresso, a Comissão Executiva Nacional de Entidades Sindicais de Assistentes Sociais (CENEAS) substituiu os homenageados - dirigentes da ditadura militar - por trabalhadores em luta por direitos e democracia, modificando o temário e a programação, com ênfase no debate das políticas sociais, dos
}

Temporalis, Brasília (DF), ano 20, n. 40, p. 30-46, jul./dez. 2020. | ISSN 2238-1856 


\section{temporoliis =ев мarconsm}

o posicionamento de parcelas significativas da categoria contra a ditadura e de ruptura com o pensamento único, conservador, fazendo avançar vários elementos e trazendo novos desafios para o exercício profissional e a formação. Inúmeras polêmicas decisivas para a superação do conservadorismo historicamente presente na profissão se colocam nas diferentes vertentes da tradição marxista: a formação profissional, a relação entre teoria, método e história, o Estado, os movimentos sociais, a democracia, a cidadania, as políticas sociais, a assistência e outras. Experiências inovadoras são realizadas, possibilitando conhecer as formas e instrumentos de organização e de luta da classe trabalhadora, os quais passam a permear a própria profissão. As inflexões do processo atingem todos os âmbitos da profissão, incluindo a formação.

No âmbito da formação, questionamentos sobre o Currículo predominante, no período, possibilitam a construção do Projeto Pedagógico e, dentro dele, das Diretrizes Curriculares. Também no ano de 1979, na cidade de Natal (RN), na XXI Convenção Nacional da ABESS ${ }^{4}$ formula-se um Currículo Mínimo, o qual é aprovado pelo Conselho Federal de Educação (CFE), em 1982. Denominado Currículo Mínimo de 1982, é nele que se dá a inclusão de reflexões sobre os movimentos sociais e sua relação com a profissão, na disciplina de Desenvolvimento de Comunidade (DC), embora a mesma já constasse do Currículo do Curso desde a década de 1960.

Lipi, Silva e Wanderley (1991) chamam a atenção para o estudo apresentado por Consuelo Quiroga no Seminário Nacional de Desenvolvimento de Comunidade (DC), realizado pela ABEPSS - Região Sul II - e pelo Programa de Estudos Pós-graduados e Pesquisa da Faculdade de Serviço Social da PUC/SP, em 1990, sobre o Currículo Mínimo de Serviço Social de 1982, com foco nas disciplinas de DC . Para Lipi, Silva e Wanderley (1991, p. 7), Quiroga mostra que os movimentos sociais aparecem nas disciplinas "expressando um jogo de forças presente naquele momento no interior da comunidade acadêmica de Serviço Social" e que, nos objetivos, há variados enfoques sobre a disciplina, embora não excludentes e, por vezes, inter-relacionados, com ênfase na instrumentalização técnica.

[...] DC enquanto instrumento das políticas sociais do Estado; compreensão dos movimentos sociais em suas relações com Estado/lgreja/Partidos, numa posição crítica ao significado 'tradicional' de DC; análise das diferentes estratégias de organização da sociedade civil e das classes subalternas (LIPI; SILVA; WANDERLEY, 1991, p. 7).

Quanto aos conteúdos, ainda conforme os autores, Quiroga enfatiza que o "tema" dos movimentos sociais "ora é resgatado através de uma análise mais global, penetrada por um modo positivista de pensar, ora numa perspectiva dialética".

movimentos sociais, das condições de trabalho dos assistentes sociais e outros. As mudanças foram decididas no III Encontro Nacional de Entidades Sindicais de Assistentes Sociais. Mesa Redonda (28 de agosto de 2009): O Congresso da Virada e os 30 anos da Revista Serviço Social e Sociedade. Revista Serviço Social e Sociedade, São Paulo, Cortez, nº 100, 2009.

${ }^{4}$ A Associação Brasileira de Ensino em Serviço Social (ABESS), em 1996, ano de aprovação das Diretrizes Curriculares passa a denominar-se Associação Brasileira de Ensino e Pesquisa em Serviço Social (ABEPSS). Neste texto, apenas neste momento nos referimos à Associação como ABESS, nos demais momentos utilizamos ABEPSS.

${ }^{5}$ A base do estudo da autora foram currículos de seis (06) Unidades de Ensino, mas os nomes das mesmas não aparecem.

Temporalis, Brasília (DF), ano 20, n. 40, p. 30-46, jul./dez. 2020. | ISSN 2238-1856 
Outros diferentes debates importantes sobre o Currículo Mínimo de 1982 tiveram andamento, no período, buscando-se identificar e superar fragilidades e insuficiências, sendo que, na Convenção Geral da ABEPSS, no ano de 1993, indica-se a necessidade de sua revisão. Tendo como pressuposto que uma revisão curricular deve se pautar por uma "[...] profunda avaliação do processo de formação profissional, face às exigências contemporâneas [...]" (ABEPSS, [20--], não paginado), entre os anos de 1994 e 1996 foram realizados diversos eventos, "[...] envolvendo a comunidade acadêmica e toda a categoria profissional em um amplo e democrático debate sobre as Diretrizes Curriculares" (ABEPSS, [20--], não paginado) ${ }^{6}$. Nos debates, dentre diferentes fragilidades e equívocos do Currículo Mínimo de 1982, do ponto de vista do nosso objeto, constata-se que os movimentos sociais são abordados sem aprofundamento, indicando-se a necessidade da busca de conhecimento sobre concepções, significado histórico nas relações de classes na sociedade do capital, tipologia relacionada à defesa de direitos, bem como das relações do Serviço Social com os mesmos.

\title{
AS DIRETRIZES CURRICULARES CONSTRUÍDAS PELA ABEPSS E AS INTERFERÊNCIAS DO IDEÁRIO NEOLIBERAL
}

A proposta de Diretrizes Curriculares, que nasce dos debates, além de defender indissociabilidade entre ensino, pesquisa e extensão, aponta diferentes aspectos para a formação de profissional com "[...] capacitação teórico-metodológica, ético-política e técnico-operativa para a apreensão teórico-crítica do processo histórico como totalidade [...]" (ABEPSS, [20--], não paginado), considerando "[...] a apreensão das particularidades da constituição e desenvolvimento do capitalismo e do Serviço Social na realidade brasileira" (ABEPSS, [20--], não paginado). Tem como pressuposto que o "Serviço Social se particulariza nas relações sociais de produção e reprodução da vida social como uma profissão interventiva no âmbito da questão social [...]" (ABEPSS, [20--], não paginado), a qual se "[...] expressa pelas contradições do desenvolvimento do capitalismo monopolista" (ABEPSS, [20--], não paginado) ${ }^{7}$. Nesse caminho, alerta para as mudanças em curso na década de 1990, com a implantação do neoliberalismo pelo governo FHC (PSDB):

\begin{abstract}
Os anos [19]9o expressam profundas transformações nos processos de produção e reprodução da vida social, determinadas pela reestruturação produtiva, pela reforma do Estado e pelas novas formas de enfrentamento da questão social, apontando, inclusive, para a alteração das relações entre o público e o privado, alterando as demandas profissionais. O trabalho do Assistente Social é, também, afetado por tais transformações, produto das mudanças na esfera da divisão sociotécnica do trabalho, no cenário mundial.
\end{abstract}

O trato rigoroso da questão social e de suas particularidades na realidade social, o trabalho e a ética, em uma perspectiva ontológica, se expressam em eixos transversais, categorias assentadas em uma perspectiva crítica e dialética. As diretrizes aprovadas em 1996:

\footnotetext{
${ }^{6}$ ABEPSS. Diretrizes Curriculares da ABEPSS. Brasília (DF), [20--]. In: http://www.abepss.org.br/diretrizescurriculares-da-abepss-10. Acesso em: 2 out. 2018.

7 ABEPSS. Diretrizes Curriculares da ABEPSS. Brasília (DF), [20--]. In: http://www.abepss.org.br/diretrizescurriculares-da-abepss-10. Acesso em: 2 out. 2018.
} 


\section{temPOCOlis}

[...] expressam inúmeros avanços, dentre eles: o amadurecimento da compreensão do significado social da profissão; a tradição teórica que permite a leitura da realidade em uma perspectiva sócio-histórica; as respostas da profissão à conjuntura e apontam para a consolidação de um projeto de profissão vinculado às demandas da classe trabalhadora (ABEPSS, [20--], não paginado).

Do ponto de vista do objeto de nosso debate, dentre os avanços, observa-se a introdução de disciplinas sobre movimentos sociais, sujeitos sociais, estratégias coletivas de organização de classe, categorias e grupos sociais, relações de gênero, étnico-raciais, identidade e subjetividade na constituição dos movimentos societários.

Aprovadas as Diretrizes em 1996, a Comissão de Especialistas da ABEPSS consolida-as em 1999, reforçando a indissociabilidade das dimensões de ensino, pesquisa e extensão, explicitando o perfil de profissional a ser formado:

- Profissional que atua nas expressões da questão social, formulando e implementando propostas para seu enfrentamento, por meio de políticas sociais públicas, empresariais, de organizações da sociedade civil e movimentos sociais. Profissional dotado de formação intelectual e cultural generalista crítica, competente em sua área de desempenho, com capacidade de inserção criativa e propositiva, no conjunto das relações sociais e no mercado de trabalho. Profissional comprometido com os valores e princípios norteadores do Código de Ética do Assistente Social.

Nas competências e habilidades, observam-se elementos oriundos da regulamentação da profissão de assistente social - Lei $\mathrm{n}^{0}$. 8662/1993:

- Assessoria e consultoria a órgãos da administração pública, empresas privadas e movimentos sociais em matéria relacionada às políticas sociais e à garantia dos direitos civis, políticos e sociais da coletividade.

Legitimando e detalhando as Diretrizes Curriculares da ABEPSS, propõe as disciplinas Classes e Movimentos Sociais e Serviço Social e Processos de Trabalho. As disciplinas interrelacionam-se no debate sobre a inserção do profissional em processos de trabalho, as estratégias profissionais, o instrumental técnico-operativo e o produto do trabalho, mostrando a relação entre questão social, políticas sociais e movimentos sociais. Insere Tópicos de Estudo abertos ao debate sobre os movimentos sociais.

$\mathrm{Na}$ análise dos dois documentos, importantes elementos ganham destaque, consolidam pontos comuns, fortalecendo-se os estudos sobre os movimentos sociais. Ou seja, expressam a importância da articulação com os movimentos sociais na formação profissional sob a direção social impressa no Projeto Pedagógico. Neles, indica-se que os movimentos sociais sejam ensinados e estudados na perspectiva das classes sociais. Sejam os que se situam no âmbito da produção - das relações de trabalho; os ligados à reprodução - de luta pela terra, moradia, meio ambiente, etc. - ou os denominados identitários - que lutam pelas questões de gênero, étnico-raciais, LGBT, etc.

Consideramos um acerto serem tratados assim, pois como coloca Marro (2014), os

Temporalis, Brasília (DF), ano 20, n. 40, p. 30-46, jul./dez. 2020. | ISSN 2238-1856 
movimentos sociais ao lutarem por direitos, na sociedade, tensionam os "[...] mecanismos estatais de enfrentamento das expressões da "questão social" e, portanto, as próprias bases de configuração da demanda profissional do Serviço Social” (MARRO, 2014, p. 278). Reforça a centralidade do trabalho, das classes sociais e da relação de forças entre elas, entendendo que, apesar das modificações ocorridas na contemporaneidade, a sociedade continua sob a égide do capital, tendo como base relações antagônicas entre capital e trabalho. Observa-se a compreensão que, sendo tipos diferentes e possuindo configurações diferenciadas, não há contradição entre os movimentos situados nas relações de trabalho daqueles que se situam na esfera da reprodução e os movimentos definidos como identitários. São tratados como movimentos sociais formados ao longo do século $X X$, de diferentes tipos, e que se encontram em um ponto que lhes é comum: a luta pela obtenção de direitos na sociedade do capital.

Na análise das Diretrizes Curriculares aprovadas pelo CNE/MEC, em 2002, constatamos significativas modificações em relação às Diretrizes da ABEPSS, de 1996, e sua consolidação pela Comissão de Especialistas, de 1999, em vários sentidos, com destaque àquelas que incidem no objeto de nosso debate.

No perfil profissional, desaparece a relação com os movimentos sociais. Consta como profissional "que atua nas expressões da questão social, formulando e implementando propostas de intervenção para seu enfrentamento", pressupondo uma "capacidade de promover o exercício pleno da cidadania e a inserção criativa e propositiva dos usuários do Serviço Social no conjunto das relações sociais e no mercado de trabalho". Desaparece a referência à Lei de Regulamentação da profissão, bem como a relação com os movimentos sociais, a qual consta apenas nas competências gerais e habilidades:

- Prestar assessoria e consultoria a órgãos da administração pública, empresas privadas e movimentos sociais em matéria relacionada às políticas sociais e à garantia dos direitos civis, políticos e sociais da coletividade (ABEPSS, [20--], não paginado).

Disciplinas que constam da proposta original da ABEPSS, consolidadas no documento da Comissão de Especialistas, como Classes e Movimentos Sociais, por exemplo, assim como os Tópicos de Estudo desaparecem das Diretrizes Curriculares do CNE/MEC.

É fundamental ressaltar que as Diretrizes Curriculares foram aprovadas pela ABEPSS, em 1996, ano da promulgação da Lei de Diretrizes e Bases da Educação (LDB), que expressava "[...] a agenda neoliberal de desmonte e flexibilização da educação brasileira e, em especial, a educação superior” (ABEPSS, [20--], não paginado). No período, o neoliberalismo, com sua perspectiva privatista do ensino superior público avançava, e, ao longo da década e inícios do século XXI, o desfinanciamento do ensino superior público e a ênfase no ensino privado foram acelerados, não ficando imune o Serviço Social.

A condução neoliberal implica em um padrão de intervenção estatal que seja máximo para o capital e mínimo para os trabalhadores (NETTO, 1996), jogando peso na transformação, em mercadoria, de todos os aspectos da vida em sociedade, significando 


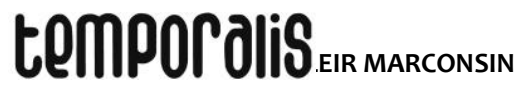

privatizações e restrições infindáveis às políticas sociais públicas. Nesse caminho, na educação, além do desfinanciamento, a ênfase também é na privatização.

De fato, é possível observar que, desde a construção e aprovação, pela ABEPSS, das Diretrizes Curriculares, em 1996, a tônica, no Brasil, é a privatização do ensino superior.

Chacon e Calderon (2015) trazem os dados sobre o fenômeno. Nos dois mandatos de FHC (PSDB - 1994 - 2002), o crescimento das Instituições de Ensino Superior privadas foi da ordem de 110,8\%. Nos dois mandatos de Lula (PT - 2003 - 2010) - embora sejam dados absolutos e não relativos -, também expressam o processo, pois mostram que foram criadas 71 instituições públicas enquanto no setor privado foi autorizado o funcionamento de 448 instituições.

Outros formatos de privatização dizem respeito ao Fundo de Financiamento Estudantil (FIES) e ao Programa Universidade para Todos (PROUNI), criados com o argumento de expansão do acesso da educação superior aos jovens da classe trabalhadora de baixos salários.

Para Leher (2015) com o valor de $\mathrm{R} \$ 13,5$ bilhões destinados ao Fies, em 2014, teria sido possível criar um número de vagas muito superior nas universidades públicas.

[...] o investimento entre 2007 e 2014 [para todas] as federais foi de $\mathrm{R} \$ 9$ bilhões e criamos, aproximadamente, 600 mil vagas, agora, em um ano [apenas] há R\$ 13,5 bilhões para o Fies. Com uma ordem de grandeza dessa, em um espaço de cinco anos estaríamos ofertando um número maior de matrículas que o sistema Fies. E não teríamos dúvidas que seriam vagas em instituições muito mais comprometidas com o conceito de formação integral e com as atividades de ensino, pesquisa e extensão (LEHER, 2015, não paginado).

O Programa Universidade para Todos (PROUNI), criado pela Lei 3.582/2004, que autoriza a compra de $10 \%$ das vagas ociosas nas universidades privadas em troca de $100 \%$ de isenção de impostos, mostra que o acesso ao ensino superior, que cresceu no governo Lula (PT), se deu "[...] prioritariamente pela continuidade do privilegiamento do setor privado em expansão, inclusive, sem regulação para se garantir a qualidade de ensino" (CADERNOS DE TEXTOS, 2011, p. 30).

\footnotetext{
Apesar do aumento de $230 \%$ nas matrículas do ensino superior na década de 1998-2008, o país encontra-se muito distante da meta contida no Plano Nacional de Educação (PNE) 2001-2010, que prevê a cobertura para, no mínimo, 30\% da população na faixa etária de 18 a 24 anos, sendo que, no mínimo, 40\% das matrículas caberiam ao setor público (CADERNOS DE TEXTOS, 2011, p. 30).
}

Entretanto, isso não ocorreu durante os governos do Partido dos Trabalhadores (Lula e Dilma - 2003-2016). Para Torkania (2017), ainda no quadro da prioridade às privatizações, o censo de 2015 mostra que o ensino presencial teve um crescimento de 2,3\% nas matrículas em relação a 2014 e o ensino a distância cresceu 3,9\%, sendo que o setor privado tem a maior concentração, representando 98\% do total das matrículas em 2015.

Trata-se de uma modalidade de ensino que a ABEPSS e o Conjunto CFESS/CRESS se posicionaram contrários à sua implantação na graduação em Serviço Social. Na formação 
em Serviço Social, também, desde a aprovação das Diretrizes Curriculares da ABEPSS, observa-se um aumento significativo do número de cursos privados e na modalidade a distância.

Para Pereira (2009), no governo Lula, de 332 cursos de Serviço Social, autorizados a funcionar entre os anos de 2003 e 2009, 91,7\% foram do setor privado. Nesse montante de cursos, mais de 50\% são de ensino a distância. Boschetti (2015) também trata da questão.

[...] [o] Serviço Social [...] saltou de 70 mil profissionais em 2006 para 135 mil ao final de 2013 e 150 mil em 2015, ou seja, em nove anos (2006-2015) alcançou um quantitativo superior àquele formado em sete décadas (1936-2006). Inegavelmente, o EAD é o maior responsável por esse crescimento assustador, acompanhado de baixa qualidade, com formação rasa e superficial, conforme amplamente denunciado pelo CFESS, em especial no documento 'Sobre a incompatibilidade entre graduação à distância e Serviço Social' (BOSCHETTI, 2015, p. 645).

Para a autora, essas ações reforçam diferentes expressões do conservadorismo no Serviço Social, mas não são endógenas à profissão; estão inseridas numa perspectiva mundial. Considera que "[...] são tendências presentes em todas as áreas, fortemente alimentadas pela contrarreforma do ensino superior forjada desde a década de 1990, no contexto da mundialização do capital" (BOSCHETTI, 2015, p. 645). Mostram-se como exigência, mas também "[...] sujeição dos países às recomendações de organismos internacionais, como Banco Mundial (BM), Organização Mundial do Comércio (OMC) e Fundo Monetário Internacional (FMI)" (BOSCHETTI, 2015, p. 643). A relação dessa direção econômico-política, do período, aparece nas mudanças impostas às Diretrizes Curriculares da ABEPSS, pelo CNE/MEC em 2002, aspecto estudado em nossa pesquisa, tanto nas disciplinas quanto nos projetos de pesquisa e extensão desenvolvidos nas Unidades de Ensino da amostra.

\section{AS UNIDADES DE ENSINO E OS MOVIMENTOS SOCIAIS: COMO APARECEM NAS DISCIPLINAS?}

Nas Unidades de Ensino estudadas, as disciplinas envolvem a temática dos movimentos sociais e o ensino do instrumental técnico-operativo profissional na relação com os movimentos sociais e aparecem como obrigatórias, eletivas, optativas ou complementares. Algumas, não têm denominação. Com o objetivo de apresentar o quantitativo das disciplinas nas Unidades de Ensino de forma clara construímos uma tabela, a qual segue abaixo.

\begin{tabular}{|c|c|c|c|c|c|}
\hline \multicolumn{7}{|c|}{ Tabela: Disciplinas sobre movimentos sociais - por curso } \\
\hline \multicolumn{7}{|c|}{ Universidades Privadas - Presencial } \\
\hline $\begin{array}{c}\text { Unidades de } \\
\text { Ensino }\end{array}$ & Obrigatórias & Eletivas & Optativas & Complementares & Total \\
\hline Castelo Branco & 01 & -- & -- & -- & 01 \\
\hline FMU & 02 & -- & -- & -- & 02 \\
\hline
\end{tabular}




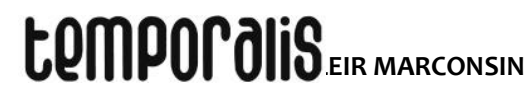

\begin{tabular}{|c|c|c|c|c|c|}
\hline \multicolumn{6}{|c|}{ Universidades Privadas - Ensino a Distância } \\
\hline $\begin{array}{c}\text { Unidades de } \\
\text { Ensino }\end{array}$ & Obrigatórias & Eletivas & Optativas & Complementares & Total \\
\hline UNIP & 01 & -- & -- & -- & 01 \\
\hline ESTÁCIO & 03 & 02 & -- & -- & 05 \\
\hline \multicolumn{6}{|c|}{ Universidades Comunitárias } \\
\hline $\begin{array}{c}\text { Unidades de } \\
\text { Ensino }\end{array}$ & Obrigatórias & Eletivas & Optativas & Complementares & Total \\
\hline PUC-RIO & 03 & -- & -- & -- & 03 \\
\hline PUC-SP & \multicolumn{4}{|c|}{06 - sem denominação } & 06 \\
\hline
\end{tabular}

\begin{tabular}{|c|c|c|c|c|c|}
\hline \multicolumn{6}{|c|}{ Universidades Públicas - Estaduais } \\
\hline $\begin{array}{c}\text { Unidades de } \\
\text { Ensino }\end{array}$ & Obrigatórias & Eletivas & Optativas & Complementares & Total \\
\hline UERJ & 04 & 05 & -- & -- & 09 \\
\hline UNESP & 03 & -- & 03 & -- & 06 \\
\hline
\end{tabular}

\begin{tabular}{|c|c|c|c|c|c|}
\hline \multicolumn{6}{|c|}{ Unidades de Ensino em Universidades Federais Existentes até 1996 } \\
\hline $\begin{array}{c}\text { Unidades de } \\
\text { Ensino }\end{array}$ & Obrigatórias & Eletivas & Optativas & Complementares & Total \\
\hline UFRJ & 04 & -- & -- & 02 & 06 \\
\hline
\end{tabular}

\begin{tabular}{|c|c|c|c|c|c|}
\hline \multicolumn{7}{|c|}{ Unidades de Ensino em Universidades Federais após 2007 } \\
\hline $\begin{array}{c}\text { Unidades de } \\
\text { Ensino }\end{array}$ & Obrigatórias & Eletivas & Optativas & Complementares & Total \\
\hline UNIFESP & 07 & -- & -- & -- & 07 \\
\hline UNIRIO & 05 & -- & 02 & -- & 07 \\
\hline
\end{tabular}

\begin{tabular}{|c|c|c|c|c|c|c|}
\hline \multicolumn{7}{|c|}{ Total geral } \\
\hline $\begin{array}{l}\text { Disciplinas em } \\
\text { duas (02) } \\
\text { Unidades de } \\
\text { Ensino em } \\
\text { Universidades } \\
\text { Privadas } \\
\text { presenciais: } \\
03\end{array}$ & $\begin{array}{l}\text { Disciplinas em } \\
\text { duas (02) } \\
\text { Unidades de } \\
\text { Ensino em } \\
\text { Universidades } \\
\text { Privadas - } \\
\text { EAD: } \\
06\end{array}$ & $\begin{array}{l}\text { Disciplinas em } \\
\text { duas (02) } \\
\text { Unidades de } \\
\text { Ensino em } \\
\text { Universidades } \\
\text { Comunitárias: } \\
09\end{array}$ & $\begin{array}{l}\text { Disciplinas em } \\
\text { duas (02) } \\
\text { Unidades de } \\
\text { Ensino em } \\
\text { Universidades } \\
\text { públicas } \\
\text { estaduais: } \\
15\end{array}$ & $\begin{array}{l}\text { Disciplinas em } \\
\text { três (03) } \\
\text { Unidades de } \\
\text { Ensino em } \\
\text { Universidades } \\
\text { públicas } \\
\text { federais: } \\
20\end{array}$ & $\begin{array}{l}\text { Total geral: } \\
\text { disciplinas }\end{array}$ & 53 \\
\hline
\end{tabular}

Numa perspectiva quantificada, podemos observar, na tabela acima, que as Unidades de Ensino públicas contêm a maior parte das disciplinas sobre movimentos sociais. Em 53

Temporalis, Brasília (DF), ano 20, n. 40, p. 30-46, jul./dez. 2020. | ISSN 2238-1856 
disciplinas, 35 são ofertadas em 05 universidades públicas (estaduais e federais), constituindo um percentual que se situa em torno de $66 \%$. Em duas (02) Unidades de Ensino comunitárias observa-se 09 disciplinas, número também significativo, considerando que são duas, enquanto nas quatro (04) Unidades de Ensino privadas presenciais e a distância - observa-se a inserção de o9 disciplinas. Ou seja, as Unidades privadas - presenciais e à distância - apresentam um número inexpressivo de disciplinas.

As 53 disciplinas estudadas aparecem nas Unidades de três maneiras:

1) Movimentos sociais em geral;

2) Movimentos sociais especificamente relativos aos direitos no âmbito da produção, da reprodução e identitários;

3) Movimentos sociais em relação ao Serviço Social.

Para expressar o conteúdo das disciplinas, coletamos dados através das ementas, dos objetivos, de unidades programáticas e de referências bibliográficas. Em algumas situações coletamos de um elemento, pois o mesmo expressava o conteúdo, em outras, foi necessária a combinação de dois ou mais elementos.

A análise do conteúdo das 53 disciplinas ofertadas pelas 11 Unidades de Ensino da amostra intencional mostra que trinta e quatro (34) disciplinas, 64,1\%, abordam os movimentos sociais em relação ao Serviço Social. Essa relação é tratada em duas perspectivas:

- Histórica - situa os movimentos sociais presentes no contexto sócio-histórico de reconhecimento da questão social, no capitalismo, - processo determinante para a gênese do Serviço Social, tanto em termos internacionais quanto no Brasil. Também nessa perspectiva, disciplinas situam a relação no contexto das lutas contra a ditadura civil-militar, no Brasil, pela democratização da sociedade e do Estado e por direitos civis, políticos e sociais, incluindo o período da Constituição de 1988.

- Atualidade: são disciplinas que debatem:

1) importância dos movimentos sociais e sua relação com o Projeto Ético-Político do Serviço Social, na busca de superação dos vínculos entre opressão, dominação e exploração de classe;

2) o instrumental técnico-operativo, buscando refletir sobre possibilidades e limites do trabalho do assistente social junto aos movimentos sociais na contemporaneidade.

Outro aspecto identificado nas disciplinas diz respeito à concepção de movimentos sociais.

Nas 53 disciplinas denota-se uma conexão com a direção social contida nas Diretrizes Curriculares da ABEPSS, que trata os movimentos sociais na perspectiva de luta por direitos na sociedade capitalista. Ou seja, com base na direção social que orienta a construção dos Currículos das Unidades de Ensino referente aos movimentos sociais, os debates se dão a partir da relação entre a economia e a política, na sociedade do capital, sem dicotomias entre essas dimensões da vida em sociedade e sem suprimir as classes sociais. São movimentos sociais que se situam no âmbito da produção, por direitos do 


\section{temPOCOliS}

trabalho, como os sindicatos - urbano e rural -, aqueles que se situam na esfera da reprodução - da luta pela terra, moradia, etc. e os identitários -que organizam a luta feminista, LGBT, geracional, étnico-raciais, etc.

Nesse caminho, a concepção pós-moderna que embasa o debate sobre os "novos movimentos sociais", na atualidade, não aparece como hegemônica nas disciplinas estudadas.

Estamos nos referindo à concepção pós-moderna que, como mostra Ribeiro (2014), ao "[...] analisar as lutas sociais na contemporaneidade [...]" tem como pressuposto "[...] que as recentes transformações societárias não permitem mais aquelas formas de referências coletivas [...]" ou de "[...] classe, que motivou as organizações sociais e políticas do século XIX e início do [...] XX” (RIBEIRO, 2014, p. 102-103). Ainda conforme a autora:

Essa forma de pensar considera que ocorre uma erosão da identidade de classe configurada na unidade ampla dos trabalhadores, predominando novas identidades de acordo com novos e múltiplos interesses, sempre parciais, e não mais universais. Assim, os interesses universais e de classes dão lugar aos desígnios grupais específicos e localistas, configurando-se nos chamados 'novos movimentos sociais' (RIBEIRO, 2014, p. 103).

Sem a pretensão de esgotar a complexidade da questão, concordando com Ribeiro (2014, p. 103), identificamos que a ideia pós-moderna tem como fundamento o "[...] fracasso da perspectiva reformista (social-democrata) e revolucionária (experiências do chamado socialismo real) [...]" (RIBEIRO, 2014, p. 103), o que leva seus pensadores a terem como premissa que essa dupla derrota "[...] implica no fim da política de classes que dá lugar a políticas de identidade" (RIBEIRO, 2014, p. 103). As novas categorias adotadas têm a perspectiva de substituir, então, as "[...] classes sociais e outras categorias marxistas [...]"(RIBEIRO, 2014, p. 103) trazendo para o debate os "novos atores" coletivos, onde se localizam as novas "significações". Para Netto (1996, p.114) a "versão neoconservadora" da "pós-modernidade" ganha espaço no meio universitário, tendo como norte a desqualificação da tradição marxista, do racionalismo dialético, equalizando-o à razão positivista, à totalidade como possibilidade de análise sistemática, que é rebaixada à "vontade totalitária"; à dinâmica histórica, que é infirmada pela ênfase nas "continuidades profundas".

O debate dos "novos movimentos sociais" aparece apenas em uma disciplina estudada, na PUC/SP, denominada "Teoria Política", em seus objetivos: "problematizar a emergência da política e do Estado modernos, seus impactos, conflitos e críticas. Analisar o poder político, econômico e ideológico e suas conexões com a sociedade organizada e os movimentos sociais. [...]. Refletir sobre práticas políticas contemporâneas, tendo como foco os novos movimentos sociais e a dimensão cultural e estética da política". Entretanto, observa-se que os "novos movimentos sociais", na disciplina, encontram-se inseridos em um debate dos conflitos e das relações entre a economia, a política e a ideologia. Nas referências bibliográficas, um autor como Stuart Hall e seu livro: “A identidade cultural na pós-modernidade", se encontra com Marx e Engels através da obra: "Manifesto do Partido Comunista". Parece-nos, então, que se trata do caminho do pluralismo, por pressupor interlocução com outras vertentes do pensamento social, na perspectiva apontada nas Diretrizes da ABEPSS, como próprio à vida acadêmica e

Temporalis, Brasília (DF), ano 20, n. 40, p. 30-46, jul./dez. 2020. | ISSN 2238-1856 


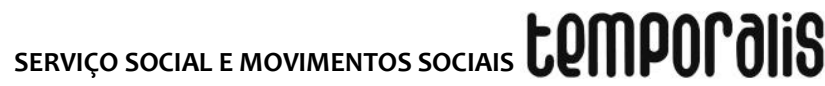

universitária, mas submetendo à crítica as várias concepções, no caminho do método dialético.

No estudo do conteúdo das disciplinas também podemos destacar a superação da insuficiência de conhecimento teórico sobre os movimentos sociais, seu significado histórico, suas formas de organização, identificadas no currículo de 1982, durante a construção das Diretrizes Curriculares da ADEPSS. Na maioria dos currículos estudados, observa-se a busca por um aprofundamento desse conhecimento sobre os movimentos sociais, exatamente na linha preconizada pelas Diretrizes Curriculares da ABEPSS.

\section{A PESQUISA E A EXTENSÃO SOBRE MOVIMENTOS SOCIAIS NAS UNIDADES ACADÊMICAS}

A pesquisa sobre movimentos sociais nas Unidades de Ensino da Amostra aparece através de projetos, programas, grupos, núcleos. As Unidades de Ensino públicas, que são cinco (05), desenvolvem dezenove (19) projetos e três (03) programas de pesquisa sobre movimentos sociais. Nas Unidades de Ensino comunitárias, que são duas (02), foi possível identificar 10 (dez) projetos e um (01) núcleo de pesquisa. Nas Unidades de Ensino privadas - presenciais e a distância - que são quatro (04) constam apenas um (01) projeto e um (01) grupo de pesquisa sobre movimentos sociais. Ou seja, a pesquisa sobre movimentos sociais e sua relação com o Serviço Social aparece em maior número nas Unidades públicas, sendo extremamente insuficiente nas Unidades privadas, presenciais e à distância.

A extensão com movimentos sociais aparece nas Unidades de Ensino da Amostra através de projetos e programas. Nelas, identificamos seis (06) projetos e um (01) programa, que são desenvolvidos nas cinco (05) Unidades de Ensino públicas. Nas Unidades comunitárias e nas privadas (presenciais e a distância) inexistem projetos ou programas com movimentos sociais.

Como nas disciplinas, os movimentos sociais que estão presentes no âmbito da pesquisa e da extensão situam-se na perspectiva posta nas Diretrizes Curriculares. São movimentos sociais que atuam no âmbito da produção - nas relações de trabalho -, relacionados à reprodução, nas lutas pela terra, moradia, em defesa da cultura, do meio ambiente, das artes, etc., que articulam as lutas identitárias, relativas a gênero, geracionais, étnicoraciais, LGBT e outras.

Observamos, assim, que em relação aos movimentos sociais, a indissociabilidade entre ensino, pesquisa e extensão é realizada de forma insuficiente, inclusive, nas Unidades de Ensino públicas da amostra, pois a extensão apresenta baixa produção, embora, em nosso entendimento, seja uma atividade fulcral para a materialização das articulações do Serviço Social com os movimentos sociais, no âmbito da formação. O fenômeno agravase nas privadas - presenciais e a distância.

A amostra intencional pode não corresponder ao conjunto das Unidades de Ensino de Serviço Social em todo o país. No entanto, o confronto entre a existência de quatro Unidades de Ensino privadas - presenciais e a distância - com um projeto de pesquisa, um grupo de pesquisa e sem ações extensionistas em relação aos movimentos sociais, com o

Temporalis, Brasília (DF), ano 20, n. 40, p. 30-46, jul./dez. 2020. | ISSN 2238-1856 


\section{temPOCOlis}

aumento significativo do número de cursos privados e na modalidade a distância desde a aprovação das Diretrizes Curriculares da ABEPSS, mostra um quadro nacional grave. Além desses dados, Pereira (2009), em sua obra "Mercantilização do ensino superior, educação à distância e Serviço Social”, constata que a maior parte das Instituições de Ensino Superior, no Brasil - não apenas referentes à formação em Serviço Social -, não se organiza no sentido de promover a relação entre ensino, pesquisa e extensão, constituindo-se, segundo a autora, mais de $90 \%$ do total, no país. Ou seja, não nos parece que a questão se restrinja apenas às Unidades da Amostra Intencional e somente aos movimentos sociais, objeto de nosso debate.

\section{CONSIDERAÇÕES FINAIS}

Como resultado dos avanços teórico-críticos ao longo dos debates encetados pelo Serviço Social, as Diretrizes Curriculares, de 1996, deram o salto de qualidade necessária ao aprofundamento do Currículo de 1982. Buscou aproximações efetivas com os movimentos sociais na prática profissional e nas lutas, mas, também, a produção de conhecimento sobre os mesmos, seu sentido histórico, seus processos, formas de participação na sociedade, etc.

No estudo desenvolvido, podemos constatar que, em significativa parte das Unidades de Ensino da Amostra, em especial nas Unidades de Ensino públicas e comunitárias, os movimentos sociais ganham espaço em várias disciplinas, superando as lacunas identificadas no processo mesmo de construção das Diretrizes Curriculares. Mas no cômputo geral das disciplinas identificadas, observa-se uma relação perceptível de continuidade com as Diretrizes Curriculares. Os currículos das Unidades de Ensino da Amostra Intencional, apesar das distorções do CNE/MEC, no que se refere ao ensino sobre os movimentos sociais, bem como as relações do Serviço Social com os mesmos, fundamentam-se nas Diretrizes Curriculares aprovadas pela ABEPSS e consolidadas pela Comissão de Especialistas.

A preocupação centra-se nas Unidades privadas, tanto presenciais quanto a distância, que apresentam um volume pequeno de disciplinas sobre movimentos sociais e também não publicizam, em suas páginas, os projetos pedagógicos, o conteúdo das mesmas, bem como os projetos de pesquisa e de extensão, o que nos impediu de conhecê-los. Mas também indica a possível inexistência dos mesmos e da indissociabilidade entre ensino, pesquisa e extensão, preconizada nas Diretrizes Curriculares da ABEPSS. Destaque-se, nesse sentido, o estudo realizado, em 2011, pelo Conselho Federal de Serviço Social (CFESS), que deu origem ao relatório intitulado "Sobre a incompatibilidade entre graduação à distancia e Serviço Social”, elencando diversas situações de irregularidades identificadas nas Unidades de Ensino a distância, dentre elas, ausência de projeto pedagógico, estágio supervisionado que descumpre as normativas postas pelos órgãos de controle da profissão, entre outras (SILVEIRA, 2019).

Esse quadro, certamente, está relacionado às modificações regressivas impostas pelo CNE/MEC às Diretrizes Curriculares que, imbricadas com a mercantilização do ensino superior, garantem a "[...] 'livre iniciativa` das unidades de ensino, públicas e privadas [...]” (UERJ, 2014, p. 4), impedindo um “[...] conteúdo básico comum à formação profissional no país" (UERJ, 2014, p. 5). Mercantilização que, dentre vários elementos, 


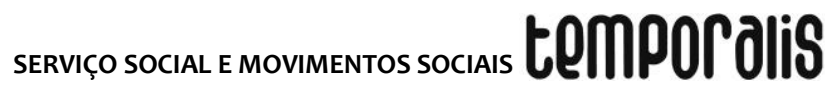

impacta negativamente na qualidade da formação profissional, seja no ensino presencial ou a distância. No contexto de profundos retrocessos vividos na contemporaneidade brasileira, o Serviço Social não ficaria imune, é atingido, também.

Nesse caminho, concordamos com Silveira (2019, p. 25-26), quando ele afirma que setores da profissão, embora não significativos, mas atuantes, travam uma "disputa por projetos profissionais", sendo uma disputa protagonizada pela "nova direita", existente na sociedade brasileira, que se expressa, também, no Serviço Social. Em seus argumentos, recorrem às "origens conservadoras do Serviço Social; influências religiosas e ecléticas [...], evocadas para uma critica global da direção social da profissão" e ao Projeto Ético-Político Profissional. Para o autor, essa "disputa por projetos profissionais" é oriunda, em sua maioria, do campo da "Educação Privada a distância". Mostra que essa "nova direita", que defende "velhos valores no Serviço Social" busca "uma unidade eclética entre a perspectiva de restauração do conservadorismo na profissão e as visões de mundo disseminadas pelas elites econômicas [...] expostas mais incisivamente na última década". As críticas da "nova direita" no Serviço Social incidem, inclusive, na ação dos movimentos sociais, na perspectiva, mesmo, da criminalização. Ainda para Silveira, (2019) observam-se críticas "[...] ao posicionamento antifascista do movimento estudantil de Serviço Social, ao movimento Feminista em geral, ao movimento \#elenão, ao movimento sindical e as mobilizações pelo "Fora Temer" (SILVEIRA, 2019, p. 19)". Ou seja, não se coloca contra, apenas, ao marxismo, mas à "mobilização social em defesa de direitos, relativiza a cultura do estupro, criminaliza mobilizações estudantis e se alinha contra toda mobilização que ameace os grupos dirigentes".

Para enfrentarmos a situação é necessário a luta em defesa do Projeto Ético-Político Profissional, a qual exige a mobilização da razão crítico-dialética, buscando entender a realidade e os rumos de sua transformação. Em nosso entendimento, o apoio e a participação nas lutas existentes na sociedade brasileira e em termos mundiais são fundamentais assim como são, também, e igualmente, estudos e atualizações sobre as articulações da profissão com os movimentos sociais no âmbito da formação, como propostas nas Diretrizes Curriculares da ABEPSS. É nesse caminho que este texto e os estudos que lhe deram origem se inserem. O norte, para eles, na atualidade, encontra-se no documento CFESS Manifesta "O trabalho de Assistentes Sociais junto aos movimentos sociais”, do XVI Encontro Nacional de Pesquisadores em Serviço Social (ENPESS), de 2018:

Em um contexto de resistência ao recuo civilizatório que vivenciamos - visto na intensa criminalização da pobreza, regressão de direitos sociais duramente conquistados e ataques à seguridade social - faz-se mais do que necessário falar

\section{REFERÊNCIAS} sobre o trabalho profissional junto aos movimentos sociais.

ABEPSS. Diretrizes gerais para o curso de serviço social. Rio de Janeiro, 1996. Disponível em: http://www.abepss.org.br/arquivos/textos/documento_201603311138166377210.pdf.

Acesso: 02 out. 2018.

ABEPSS. Diretrizes Curriculares elaboradas pela equipe de especialistas de 1999. Rio de Janeiro, 1999. Disponível em:

http://www.abepss.org.br/arquivos/textos/documento_201603311140412406970.pdf.

Acesso: 10 out. 2018.

Temporalis, Brasília (DF), ano 20, n. 40, p. 30-46, jul./dez. 2020. | ISSN 2238-1856 


\section{tempOralis}

\section{ABEPSS. Diretrizes Curriculares para os Cursos de Serviços Sociais aprovada pelo MEC}

em 2002. Rio de Janeiro, 2002. Disponível em: http://www.abepss.org.br/arquivos/textos/documento_201603311141012990370.pdf Acesso: 22 out. 2018.

ABEPSS. Diretrizes Curriculares da ABEPSS. Brasília (DF), [20--]. Disponível em: http://www.abepss.org.br/diretrizes-curriculares-da-abepss-10. Acesso em: 2 out. 2018.

BOSCHETTI, I. Expressões do conservadorismo na formação profissional. Serv. Soc. Soc., São Paulo, n. 124, p. 637-651, out./dez. 2015. Disponível em:

https://www.scielo.br/pdf/sssoc/n124/0101-6628-sssoc-124-0637.pdf. Acesso em: 13 dez. 2020.

CADERNOS DE TEXTOS $30^{\circ}$ CONGRESSO DO ANDES-SINDICATO NACIONAL. Uberlândia (MG), 14 a 20 de fev. 2011. Disponível em:

https://aduferpe.org.br/downloads/caderno_de_textos_do_30congresso_andes_sn.pdf. Acesso em: 24 dez. 2020.

CHACON, J. M. T., CALDERON, A. I. A expansão da educação superior privada no Brasil: do governo de FHC ao governo de Lula. Revista Iberoamericana de Educación Superior, México, v. 6, n. 17, p. 78-100, set./dez. 2015. Disponível em: https://doi.org/10.1016/j.rides.2015.10.004. Acesso em: 7 jul. 2018.

CFESS. O trabalho de Assistentes Sociais junto aos movimentos sociais. Brasília: CFESS Manifesta, 2018. Disponível em: http://www.cfess.org.br/arquivos/2018-CfessManifesta16Enpess-GTPAbepss-site.pdf. Acesso em: 20 maio 2014.

FONTANELLA, Bruno José Barcellos; RICAS, Janete; TURATO, Egberto Ribeiro. Amostragem por saturação em pesquisas qualitativas em saúde: contribuições teóricas. Cad. Saúde Pública, Rio de Janeiro, v. 24, n. 1, p. 17-27, jan. 2008. Disponível em: https://www.scielo.br/scielo.php?script=sci_arttext\&pid=S0102-311X2008000100003. Acesso em: 13 dez, 2020.

LEHER, R. Novo reitor da UFRJ afirma que universidades públicas poderiam gerar o dobro de vagas do Fies com o mesmo investimento. Jornal O Globo, 03 jul. 2015. Disponível: https://oglobo.globo.com/sociedade/educacao/novo-reitor-da-ufrj-afirma-queuniversidades-publicas-poderiam-gerar-dobro-de-vagas-do-fies-com-mesmo-investimento16655995. Acesso em: 14 dez. 2018.

LIPI, L. B. SILVA, M. L. C. WANDERLEY, M. B. Seminário Nacional de Desenvolvimento de Comunidade. Revista Serviço Social e Sociedade, São Paulo, ano XII, n. 36, P. 03-12, 1991.

NETTO, J. P. Ditadura e Serviço Social: uma análise do Serviço Social no Brasil pós-64. São Paulo: Cortez, 1991. 


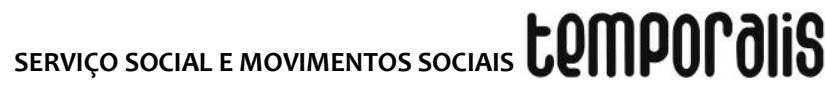

NETTO, J. P. Transformações societárias e Serviço Social: notas para uma análise prospectiva da profissão no Brasil. Revista Serviço Social e Sociedade, São Paulo, n. 50, p. 87-132, 1996.

MARRO, K. I. O que a universidade pode aprender quando coloca seus pés em um acampamento sem terra? In: Movimentos Sociais e Serviço Social: uma relação necessária. ABRAMIDES, M.B., DURIGUETTO, M.L. (orgs.). São Paulo: Cortez, 2014, pp. $278-294$.

MARRO, K. I. O que a universidade pode aprender quando coloca seus pés em um acampamento sem-terra? In: ABRAMIDES, M. B.; DURIGUETTO, M. L. (org.). Movimentos Sociais e Serviço Social: uma relação necessária. São Paulo: Cortez, 2014.

PEREIRA, L. D. Mercantilização do ensino superior, educação à distância e Serviço Social. Katálysis, Florianópolis: Revista do Programa de Pós-Graduação em Serviço Social, Curso de Serviço Social da Universidade Federal de Santa Catarina, v. 12, n.2, p. 268-277, jul./dez. 2009. Disponível em: https://periodicos.ufsc.br/index.php/katalysis/article/view/S141449802009000200017. Acesso em: 24 dez. 2020.

REVISTA SERVIÇO SOCIAL E SOCIEDADE: O Congresso da Virada e os 30 anos da Revista. São Paulo, Cortez, n. 100, p. 593-800, out./dez. 2009.

RIBEIRO, S. P. F. Lutas sociais contemporâneas: entre os desígnios pós-modernos e os imperativos da classe trabalhadora. In: In: ABRAMIDES, M. B.; DURIGUETTO, M. L. (org.). Movimentos Sociais e Serviço Social: uma relação necessária. São Paulo: Cortez, 2014, p. 102-118.

SILVEIRA, J. R. S, da. Contribuição para pesquisa do conservadorismo ultraliberal na redefinição de projetos profissionais: a "nova” direita vai ao Serviço Social. In: Colóquio Internacional Marx e o Marxismo, 2019, Niterói. Anais [...]. Niterói: UFF, 2019. p. 16-29. Disponível em:

http://www.niepmarx.blog.br/MManteriores/MM2019/Trabalhos\%20aprovados/MC47/MC 472.pdf. Acesso em: 05 abr. 2020.

TOKARNIA, M. Educação superior a distância cresce em ritmo acelerado. Agência Brasil, 28 maio 2017. Disponível em: https://agenciabrasil.ebc.com.br/educacao/noticia/201705/educacao-superior-distancia-cresce-em-ritmo-acelerado-mostra-censo-de-2015. Acesso em: 12 ago. 2017.

UERJ. Currículo pleno do curso de graduação em serviço social. Rio de Janeiro: UERJ, 2014. 


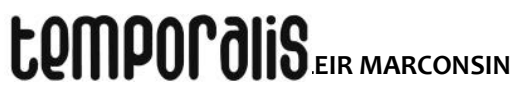

\author{
Cleir MARCONSIN \\ Assistente social, formada pela Pontifícia Universidade Católica de Campinas (PUCCAMP) em 1975. Mestre em \\ Serviço Social pela Universidade Federal da Paraíba (UFPB) com término em 1997 e doutora, também em \\ Serviço Social, pela Universidade Federal do Rio de Janeiro (UFRJ) em 2009. É docente da Faculdade de \\ Serviço Social da Universidade do Estado do Rio de Janeiro (UERJ) desde 1998 e tem a articulação trabalho, \\ direitos, movimentos sociais e Serviço Social como eixo de estudo. Pesquisadora do Observatório do Trabalho \\ e Políticas Públicas da Faculdade de Serviço Social da UERJ. \\ Pós-doutora formada pelo Programa de Estudos Pós-graduados em Serviço Social da PUC-SP.
}

